\title{
ATENÇÃO À SAÚDE MENTAL NA ESTRATÉGIA SAÚDE DA FAMÍLIA: RECURSOS NÃO RECONHECIDOS'
}

\author{
Mariana de Oliveira Pasqualin Ribeiro* \\ Departamento de Medicina Social, Faculdade de Medicina de Ribeirão Preto, \\ Universidade de São Paulo, Ribeirão Preto, SP, Brasil \\ Maria do Carmo Gullaci Guimarães Caccia-Bava \\ Departamento de Medicina Social, Faculdade de Medicina de Ribeirão Preto, \\ Universidade de São Paulo, Ribeirão Preto, SP, Brasil \\ Carla Guanaes-Lorenzi \\ Departamento de Psicologia, Faculdade de Filosofia, Ciências e Letras de Ribeirão \\ Preto, Universidade de São Paulo, Ribeirão Preto, SP, Brasil
}

Resumo: Um dos pilares da política de Atenção Básica, a Estratégia Saúde da Família, realiza assistência descentralizada nos territórios adscritos, atendendo diferentes demandas, incluindo a saúde mental. Esta pesquisa teve como objetivo produzir sentidos com profissionais da Saúde da Família sobre seus recursos para o cuidado em saúde mental. Para tanto, foram realizados grupos focais com profissionais da saúde da família de um município do interior do estado de São Paulo. A análise do material foi realizada por procedimentos qualitativos de análise temática, com base nas contribuições do movimento construcionista social. Essa análise permitiu dar visibilidade a importantes recursos técnicos e relacionais da equipe para o

1 Artigo original, derivado da dissertação de mestrado intitulada “Recursos e necessidades de profissionais da Estratégia Saúde da Família para lidar com questões relacionadas à Saúde Mental", de autoria de Mariana de Oliveira Pasqualin Ribeiro, defendida junto ao Programa de Pós-Graduação em Saúde na Comunidade do Departamento de Medicina Social da Faculdade de Medicina de Ribeirão Preto - USP.

Dados apresentados resultantes de projeto de pesquisa aprovado pelo Comitê de Ética em Pesquisa do Centro de Saúde Escola da Faculdade de Medicina de Ribeirão Preto da USP (Protocolo no. 330/CEP-CSE-FMRP-USP).

* E-mail para correspondência: marianapasqualin@yahoo.com.br 
cuidado em saúde mental, mas que pareciam pouco legitimados em seu cotidiano. Discutimos a necessidade de criação de espaços de reflexão onde os trabalhadores de saúde possam ressignificar suas ações, o que pode contribuir para a qualificação do atendimento em saúde mental na Atenção Básica.

Palavras-chave: Atenção primária à saúde. Estratégia saúde da família. Saúde mental. Construcionismo social.

\section{Introdução}

A Saúde da Família, criada no início da década 1990, foi idealizada como uma estratégia de reorientação do modelo assistencial, visando superar a fragmentação presente no modelo biomédico, a partir do estabelecimento de vínculos positivos entre a equipe de saúde e os cidadãos e grupos familiares moradores em território de adscrição.

Nesse sentido, o eixo norteador da política de Atenção Básica (AB), na qual a Estratégia Saúde da Família (ESF) é a forma prioritária de organização do modelo assistencial, tem sido o compromisso com a intervenção nos processos de adoecimentos por meio de ações orientadas com base na comunidade. Essa mudança do modelo exige também uma mudança no processo de trabalho da equipe de saúde, que deixa de focar as doenças e passa a ter seu foco dirigido também à promoção e manutenção da saúde (Marqui et al., 2010).

Segundo Pereira (2000), a atuação da equipe de saúde da família é extremamente vasta e plástica pelas diferentes demandas que surgem dentro da comunidade, pelo tipo de relação construída com as equipes e as articulações com organismos e instituições sociais. Assim, o cuidado à Saúde Mental é considerado como uma das responsabilidades da ESF, já que muitas situações dessa natureza são experimentadas pelas famílias atendidas por essas equipes.

Para Souza (2004), cabe à equipe de saúde da família desenvolver propostas de cuidados que incluam a Saúde Mental, partindo das situações observadas em seu cotidiano profissional e do conhecimento dos recursos disponíveis. Pode-se dizer que todo problema de saúde é, também e sempre, um problema de saúde mental e toda saúde mental é uma produção de saúde, o que torna importante e necessária a articulação da Saúde Mental com a AB (Brasil, 2003).

Diferentes estudos relatam que as equipes de $A B$ deparam, cotidianamente, com a necessidade de enfrentar problemas de saúde mental (Amarante, Lepre, Gomes, Pereira \& Dutra, 2011; Correia, Barros \& Colveiro, 2012; Mielke \& Olchowsky, 2011; Rosa \& Labate, 2003; Souza \& Luis, 2012; 
Vecchia \& Martins, 2009a). Segundo Scóz e Fenili (2003), tem sido crescente na ESF a demanda pela atenção aos transtornos psíquicos leves mais prevalentes, manifestados sob diferentes formas, entre elas os quadros depressivos e os transtornos de ansiedade. Como sintetizam Souza e Luis (2012), "o portador de transtornos mentais tem maior risco para doenças e agravos, por outro lado, muitas condições de saúde potencializam a vulnerabilidade para os transtornos mentais" (p. 853).

O campo da Saúde Mental tem como maior desafio capacitar as equipes da $A B$ para pensar e agir sem recorrer às velhas estruturas, seguindo, desse modo, as diretrizes da reforma psiquiátrica (Brasil, 2005). Isso implica o esforço de construir, no dia a dia do trabalho, dispositivos que possam efetivamente ajudar as pessoas a cuidar melhor da saúde e reorganizar suas vidas. Esse trabalho deve ser feito em parceria com as famílias e a comunidade, ampliando a capacidade de escuta das equipes (Gonçalves, 2000).

Pensando no fortalecimento da ESF e na melhoria da resolubilidade na $A B$, o Ministério da Saúde propôs a criação dos Núcleos de Apoio à Saúde da Família (NASF). Esses núcleos devem ser constituídos por profissionais de diferentes áreas de conhecimento, que atuarão em parceria com os de Saúde da Família, participando diretamente no apoio a essas equipes (Brasil, 2009).

O apoio matricial busca conhecer e interagir com as equipes da $A B$ em seu território, atendendo conjuntamente situações complexas e levantando dados relevantes sobre as demandas em Saúde Mental (Mielke \& Olchowsky, 2010; Rabelo \& Tavares, 2008). Essa equipe deve funcionar com o objetivo de assegurar retaguarda à equipe e aos profissionais da $A B$, oferecendo um suporte técnico pedagógico, objetivando ampliar as possibilidades de realizar-se a clínica ampliada (Brasil, 2007) e a integração dialógica entre distintas especialidades e profissões (Campos \& Domitti, 2007; Silva, Santos \& Souza, 2012).

Lancetti (2000) reúne descrições e relatos de experiências em diferentes municípios do país, discutindo, a partir disso, a necessidade de integração entre a Saúde Mental e a Saúde da Família. Para o autor, faz-se necessário uma maior aproximação entre essas duas áreas da saúde, com equipes que priorizam o trabalho na família e na comunidade e que buscam o exercício da cidadania de pessoas com transtorno mental. Essa estratégia de atenção requer mudanças na postura e na formação profissional, exigindo um trabalho psíquico e uma capacitação continuada. O vínculo formado com as famílias e a proposta de continuidade exigem lidar com o sofrimento humano, mas esse é um processo para o qual os técnicos, muitas vezes, não estão preparados.

Souza (2004) também discute a importância do suporte técnico para os profissionais de saúde da família e considera que a realização de treinamentos e orientações propicia maior resolubilidade do serviço às 
demandas de saúde mental e ainda melhoram o envolvimento dos usuários com transtorno mental e sua família. Para Gonçalves (2000), a ESF requer das equipes um manejo instrumental das próprias ansiedades e o desenvolvimento de uma atitude afetiva e solidária diante da realidade da comunidade e de seu sofrimento.

Segundo Figueiredo e Campos (2008), uma pesquisa do Ministério da Saúde de 2003 mostra que 56\% das equipes de ESF referem realizar "alguma ação de Saúde Mental", mesmo que essas equipes nem sempre estejam capacitadas para lidar com esta demanda. Também Rabelo e Tavares (2008) enfatizam a importância da reflexão e pesquisa sobre as novas práticas que se inserem no processo da reforma sanitária brasileira, que se justificam pelas deficiências das equipes de ESF quanto às atuações em Saúde Mental, muito influenciadas pelo modelo biomédico.

O presente artigo dialoga com estes estudos científicos que apontam os desafios de integração dos cuidados à Saúde Mental na $A B$, e que reforçam essa necessidade. Por ser a Saúde da Família uma estratégia tão relevante para o fortalecimento da $A B$, consideramos fundamental compreender como os profissionais da ESF significam sua atuação e lidam com a possível falta de preparo para assistir problemas relacionados à Saúde Mental. Por outro lado, esse artigo prioriza, como seu objetivo central, apresentar sentidos construídos com trabalhadores da ESF sobre seus recursos para lidar com questões relacionadas à Saúde Mental, em detrimento de suas deficiências e falhas.

\section{Método}

\section{Delineamento teórico-metodológico}

Essa pesquisa se desenvolveu com base nas contribuições do movimento construcionista social para compreensão do processo de produção do conhecimento. Esse movimento valoriza o entendimento de como as pessoas constroem, por meio de sua participação em práticas discursivas social, histórica e culturalmente situadas, sentidos sobre si mesmas e sobre o mundo em que vivem (Gergen, 1997). Marca-se, assim, uma diferença epistemológica significativa em relação às propostas realistas em ciência, a partir do entendimento de que nosso conhecimento sobre o mundo se entrelaça às possibilidades de significá-lo.

Esse entendimento traz implicações importantes para a prática de pesquisa: a compreensão do significado como resultado de uma "ação conjunta" (Shotter, 2005) de uso da linguagem, ao invés da busca por um significado intrínseco à palavra ou texto; a ênfase na participação do pesquisador no processo de construção desse conhecimento, no lugar de sua neutralidade; o reconhecimento do caráter local e situado do conhecimento pro- 
duzido, em vez da busca pela generalização; o compromisso pela explicitação das escolhas do pesquisador e passos de interpretação, ao invés do controle de possíveis vieses dessa participação (Spink \& Menegon, 1999). Desse modo, a dialógica que atravessa o processo de pesquisa é característica de uma investigação construcionista, da escolha do tema, à constituição do estudo e sua análise e discussão (McNamee \& Hosking, 2012).

\section{Aspectos éticos}

O projeto de pesquisa do qual deriva esse artigo foi avaliado e aprovado por um Comitê de Ética em Pesquisa e seguiu todas as recomendações legais e éticas necessárias à boa prática de pesquisa, atendendo à Resolução 196/96 sobre Pesquisas Envolvendo Seres Humanos. Os profissionais de saúde concordaram em participar da pesquisa voluntariamente, assinando Termo de Consentimento Livre e Esclarecido. Para garantir o sigilo das informações, utilizamos letras para nos referirmos às unidades de saúde do município e nomes fictícios para nos referirmos aos participantes da pesquisa e aos pacientes citados por eles em seus relatos.

\section{Contexto e participantes}

O município onde foi realizada a pesquisa está localizado na região nordeste do estado de São Paulo, possuindo população de aproximadamente 11.000 habitantes. A Rede Municipal de serviços de saúde é constituída de uma Unidade Mista de Saúde, que realiza atendimentos de emergência e clínicos (clínica médica, pediatria, ginecologia, ortopedia, dentista, fisioterapeuta, psicólogo e fonoaudiólogo). A partir de 2010, o município passou a contar com atendimentos quinzenais de psiquiatria. Atendimentos de média e todos os de alta complexidade são realizados por municípios vizinhos.

O município conta ainda com duas Unidades de Saúde da Família, que atendem juntas a cerca de 1800 famílias. Até o momento de desenvolvimento da pesquisa, os profissionais dessas equipes não recebiam apoio de equipes de matriciamento. Também nunca tinham recebido qualquer treinamento ou capacitação em Saúde Mental.

Participaram da pesquisa todos os profissionais das duas unidades de saúde da família, que atuavam na equipe há mais de seis meses. Adotamos um tempo mínimo de trabalho na equipe como critério de inclusão para garantir que os profissionais tivessem certa vivência de trabalho na ESF e que fossem conhecedores do processo de trabalho da equipe a que pertenciam. No total, participaram 17 profissionais de saúde - sendo oito na equipe $A$, e sete na equipe $B$. Cada equipe era composta por um médico, um enfermeiro, um auxiliar de enfermagem, um recepcionista e de 4 a 5 agentes comunitários de saúde (ACS). 


\section{Procedimentos de constituição do "corpus"}

Foram realizadas entrevistas em grupo com todos os trabalhadores das duas equipes, utilizando-se a técnica do grupo focal. Esta consiste em uma discussão temática, dirigida pelo pesquisador, e que pode ser utilizada em investigações voltadas à compreensão de como se constroem conjuntamente diferentes sentidos sobre um conceito, uma prática ou um serviço (Kind, 2004; Llanes, 2005).

Para o desenvolvimento dessas entrevistas, utilizou-se um roteiro semiestruturado, contendo temas gerais: concepções sobre saúde mental, relações entre ESF e Saúde Mental, capacitação para o trabalho com a saúde mental e manejo de tais problemáticas no cotidiano. Em ambos os grupos, a discussão foi iniciada com a questão geral: "O que é Saúde Mental para vocês?".

Foram realizados dois encontros de grupo, um com cada equipe de saúde. A duração desses encontros foi de aproximadamente uma hora e vinte minutos. Os grupos foram coordenados pela primeira autora desse artigo e observados pela segunda autora. As conversas foram audiogravadas e foram feitos registros sobre o desenvolvimento dos grupos e interação entre os participantes.

\section{Procedimentos de análise}

O início da análise se deu com a transcrição integral e literal das conversas de grupo, preservando a linguagem coloquial dos participantes. Na sequência, iniciamos a leitura exaustiva das sessões transcritas, buscando construir maior familiaridade com o material produzido. Com essa leitura, intentamos tanto dar visibilidade a alguns temas que atravessaram o diálogo nos grupos de discussão, como também compreender aspectos importantes da interação entre os participantes.

Em relação às interações desenvolvidas nos grupos, observamos, nessa pré-análise, que a entrevista com a Equipe $A$ apresentava uma maior diversidade de sentidos, produzidos por um diálogo mais democrático e envolvido entre os participantes. Nessa entrevista, as relações estabelecidas foram mais horizontais, fazendo que as diferenças de formação, conhecimento, status social e gênero, mesmo existindo, não impedissem o diálogo. Escolhemos, desse modo, focalizar essa entrevista em nossa análise. Essa equipe é composta por nove profissionais, sendo: um médico (João), uma enfermeira (Joana), uma auxiliar de enfermagem (Marina), uma recepcionista (Zulmira) e cinco agentes comunitárias de saúde (Ana, Lia, Marta, Tatiana e Vanessa).

Em relação aos temas discutidos, percebemos, também em nossa pré-análise, haver dois movimentos importantes no desenvolvimento dos grupos: um deles era marcado pelo predomínio do que denomina- 
mos "discurso do déficit" (Gergen, 1997), em que os profissionais falam de suas dificuldades para lidar com as questões de saúde mental. Assim como descrito em estudos semelhantes (Oliveira, Ataíde, \& Silva, 2004; Ribeiro, Medeiros, Albuquerque \& Fernandes, 2010; Souza \& Luis, 2012), os profissionais discutiam as necessidades, a falta de recursos e as dificuldades para trabalhar com questões de saúde mental na AB. Porém, um outro movimento nos pareceu igualmente importante, porém pouco valorizado pelos participantes nos grupos. Ao descreverem suas ações concretas no trato cotidiano com as questões de saúde mental, os profissionais de saúde mostravam ter muitos recursos, técnicos e relacionais, que também eram indicativos de preparo e disponibilidade para lidarem com tais questões, embora parecessem não reconhecê-los como tal.

Tendo como suporte as reflexões de Shotter (2005) acerca da pesquisa, buscamos, em nossa análise, valorizar essa dimensão diferente e inusitada do diálogo, entendendo que a mesma poderia acrescentar um aspecto importante ao conhecimento já produzido sobre esse tema. Nesse sentido, buscamos, por meio de uma análise qualitativa temática, nomear alguns recursos e habilidades construídos no diálogo com os participantes da pesquisa, assim dando visibilidade a importantes modos de cuidado em Saúde Mental na AB. Consideramos, tal como afirmam Spink e Menegon (1999), que categorias constituem-se práticas discursivas e, sendo assim, não descobrem uma dada realidade, mas a constroem como tal. Assim, as categorias de análise funcionam como "estratégias linguísticas delineadas para conversar, explicar, organizar e dar sentido ao mundo, cujas especificidades estão vinculadas ao contexto que as produzem" (Spink \& Menegon, 1999, p. 79).

Nesse sentido, as categorias construídas e apresentadas a seguir intencionalmente nomeiam recursos, convidando o leitor a refletir sobre possíveis implicações do não reconhecimento dos mesmos para a prática dos profissionais de saúde. São elas: a) acompanhamento, envolvimento e disponibilidade; b) reconhecimento das necessidades de saúde; c) prevenção e parceria com os serviços especializados; d) capacidade de escuta e diálogo; e) acompanhar e prestar socorro em situações de risco; e f) construção de vínculos de confiança e respeito. Para cada categoria, selecionamos fragmentos de diálogos desenvolvidos entre os participantes do grupo que ilustram o processo a ser discutido.

\section{Resultados e discussão}

A seguir, apresentamos alguns fragmentos do diálogo com os profissionais da Equipe A, em que recursos para o trabalho com Saúde Men- 
tal foram construídos, todavia sem ser assim nomeados, não sendo legitimados e reconhecidos pela equipe.

\section{Acompanhamento, envolvimento e disponibilidade}

Quando a pesquisadora convidou a equipe a refletir sobre o que seria necessário para que os profissionais de saúde se sentissem preparados para lidar com pacientes com queixas de saúde mental, eles falaram sobre a necessidade de capacitação e treinamento. Joana ressalta que seria necessário um atendimento em grupo para a equipe, que precisa "extravasar", destacando a necessidade da equipe "ser cuidada". Nesse momento, Lia descreve uma experiência que teve ao acompanhar três pacientes em crise a um ambulatório de saúde mental em uma cidade vizinha:

Lia: deixa eu te contar uma experiência.... Tava eu e a Jack (funcionária da Prefeitura responsável pelo agendamento de consultas em um hospital geral), nós fomos levar o Otacílio, a Helena, que é irmã do Otacílio e a D. Leila na Saúde Mental. Os três estavam surtados... Lá, era para internar a D. Leila e eles não internam, tinha que sair daqui a regulação. E ela tava tão surtada que ela ficava assim "Lia, Lia, Lia... Pedro, Pedro, Pedro... Jack, Jack, Jack...". Ela brigou com todo mundo na Saúde Mental, e a mulher queria colocar nós para fora.... Isso eram 4 horas da tarde quando eles passaram pra pegar a gente lá. Nós saímos daqui 7 horas da manhã. Eu sei que no final das contas eu que fui pro Pronto Socorro, porque me deu uma crise de bronquite que eu quase morri lá... É complicado porque você pega a carga pra você deles....

Joana: Por esse exemplo que a Lia deu, a Saúde Mental também, sendo Saúde Mental, colocar eles pra fora, eles também não tão preparados. (p. 5, L. 26-35)

Nesse trecho, Lia relata uma situação de grande envolvimento com o cuidado em saúde mental. Jack e ela foram designadas para acompanhar três pacientes em crise a um serviço especializado. Em seu entendimento, como os pacientes estavam "surtados" (termo bastante pejorativo e que posiciona os pacientes como incapazes de responder por si mesmos), a única solução era a internação psiquiátrica. No entanto, ao contrário do que esperavam, lá depararam com profissionais que também não pareciam preparados para acolher aquela situação de crise e que cobravam delas alguma solução. Assim como aponta a literatura da área (Campos \& Gama, 2010; Vecchia \& Martins, 2009a), este momento exemplifica as dificuldades que as equipes de saúde encontram, no cotidiano, para desenvolver o cuidado em saúde mental, e a carência de serviços especializados para apoio nas situações de crise (Lancetti, 2000; Souza, 2004).

A situação trouxe grande desgaste à Lia, que significou a crise de bronquite que teve nesse dia como decorrência dessa vivência - entendimento que reafirma a necessidade de preparo, tanto técnico como 
emocional, dos profissionais de saúde para sua atuação. No entanto, a despeito do desafio, Lia e Jack permaneceram junto desses pacientes, demonstrando acolhimento, envolvimento e disponibilidade, e brigando pelo direito deles serem atendidos com dignidade.

\title{
Reconhecimento das necessidades de saúde
}

Em continuidade ao diálogo anterior, Zulmira e Ana discutem o despreparo do serviço social para entender algumas demandas como necessidades de saúde:

\begin{abstract}
Zulmira: Eu acho que o serviço social deixa a desejar, eles não se preocupam muito, pra resolver um problema demora muito também... Sabe, e a pessoa tem que se humilhar muito também, a pessoa já tem um problema, aí chega lá tem que se humilhar, às vezes a pessoa fica pior ainda.... Eu tô fazendo serviço social, eu tô tentando aposentar o Otacílio. Nem tenho obrigação, mas tô fazendo por caridade, sabe, de ver a situação deles, tudo... Porque com um dinheirinho, lá vai ficar tudo bem... Não vai dar trabalho pra nós...
\end{abstract}

Ana: É até melhor pra gente.

Zulmira: Porque a Helena tendo dinheiro, o Otacílio tendo dinheiro, eles ficam bem... Tô tentando, tipo assim, ajudar. Vamo vê. (p. 5, L. 48; p. 6, L. 9)

Apesar de ainda se pautar em um discurso assistencialista de cuidado ("nem tenho a obrigação, mas tô fazendo por caridade"), ao analisar a situação de vida de dois pacientes com transtornos mentais acompanhados pela equipe, Zulmira consegue identificar que uma aposentadoria seria importante para melhorar a convivência dos dois, pois não têm recursos para se manterem, o que muitas vezes os desestabiliza. Dessa forma, Zulmira tenta colocar em prática tanto a análise dos determinantes sociais da saúde (Buss \& Pellegrini Filho, 2007), como de necessidades de saúde (Cecílio, 2001; Egry, 2008), ampliando as possibilidades do cuidado oferecido nestes casos.

\section{Prevenção e parceria com serviços especializados}

Logo após a reflexão de Zulmira, emergiu na conversa da equipe o sentido de que a ESF deve trabalhar com a prevenção, e que apenas após o aparecimento da doença mental os pacientes deveriam ser encaminhados ao atendimento especializado. A partir disso, os profissionais contam sobre um trabalho desenvolvido em parceria com uma fisioterapeuta, de ajuda a pacientes com depressão por meio de massagens, relaxamento e ioga. Este grupo é definido como um trabalho em Saúde Mental na AB, 
que atende pessoas com transtornos mentais leves, assim evitando o seu encaminhamento para outros níveis de atenção.

Joana: a gente do PSF tem que trabalhar antes pra que eles não venham a ficar doente...Com a prevenção, né, e aí a partir do momento que elejá ta com o problema mental, já tá doente mental, aí ele seria encaminhado pra esse ambulatório. Porque, nossa, é muito difícil...

Vanessa: Porque o PSF, nós, não tem como você tratar, implantar ali a Saúde Mental, mas assim, como o doutor falou, a prevenção sim.... Teria que ter realmente esse ambulatório pra eles serem tratados lá e assim, a gente com parceria com eles, na fiscalização, nós agentes vendo se eles estão tomando a medicação, colaborando... por isso que tem que ter só a Saúde Mental e a gente com prevenção e ajuda. E isso a gente já faz no Círculo do Amor, o grupo que a gente tem com a fisioterapeuta que trata um pouco isso né... Depressão, o físico... e a mente, com ioga, né?

Ana: Massagens, relaxamento...

Vanessa: A pessoa aprendendo a se conhecer, até pra gente mesmo...

Ana: A lidar com as emoções no momento certo. Ela tá focalizando isso com a gente. (p. 6, L. 29-51)

Apesar da ênfase dada pelos participantes à necessidade de encaminhamento e do trabalho "apenas" com a prevenção e fiscalização (este último termo é bastante problemático uma vez que pode ser visto como contrário ao fortalecimento da autonomia dos pacientes), a valorização da parceria com os serviços especializados e da atuação do agente no acompanhamento do doente mental também tiveram espaço nesse diálogo. Dessa forma, os sentidos construídos no grupo guardam relação com o que aponta a literatura da área, e reforça a necessidade de fortalecimento da articulação entre os serviços de saúde (Cecilio, 2001; Brasil, 2005; Vecchia \& Martins, 2009b).

Além disso, os profissionais também valorizam a ajuda oferecida pelos grupos de prevenção, tanto para os pacientes como para sua própria saúde mental. Esse se constitui um momento interessante, em que os profissionais se aproximam dos pacientes, percebendo o cuidado à saúde mental como uma necessidade de todos.

\section{Capacidade de escuta e diálogo}

Em outro momento, Zulmira trouxe para a conversa a capacidade da equipe de ouvir e conversar com os pacientes, contando que os pacientes reconhecem esse tipo de ajuda e se beneficiam dela. Joana fala 
do cansaço que essa disponibilidade traz para a equipe, que muitas vezes se sente esgotada, enquanto Lia valoriza o vínculo como recurso para se efetivar essa ajuda.

Zulmira: E outra, às vezes parece que a Joana que é a psicóloga lá. O pessoal chega lá e fala "Preciso falar com você.... Aí a Joana conversa, conversa e a pessoa sai bem. No outro dia parece que é o retorno: "Ai Joana eu tô bem, vim conversar com você de novo".

Joana: Ai, isso vai cansando e a gente que não vai aguentando mais. Ejá não tem um ambiente adequado, né, não tem sala pra enfermeira lá...

Lia: Mas nós na visita... a partir do momento que você já conhece a pessoa eles têm a liberdade de chegar pra você e contar o problema deles, eles acham assim, eu vou contar e ela vai tentar resolver meu problema, então fica bem mais fácil quando você tem um vínculo. (p. 8, L. 33-46)

A visita domiciliar é descrita como um instrumento de aproximação e favorecimento do vínculo da equipe com os pacientes, que sentem liberdade para expor seus problemas e pedir ajuda à equipe. No entanto, esse cuidado (que envolve escuta e diálogo) sobrecarrega os profissionais de saúde, que questionam se esse trabalho deveria ser feito por um especialista ("às vezes parece que a Joana que é a psicóloga lá"). Assim, embora signifiquem esse tipo de ajuda como benéfico para a comunidade, os profissionais reforçam o peso que isso acarreta em seu cotidiano, pois não se sentem aptos para essa função (" $A i$, isso vai cansando e a gente que não vai aguentando mais"). Também aqui a análise de Lancetti (2000) se faz pertinente: o vínculo formado com as famílias impõe a necessidade de lidar com o sofrimento humano, sendo este um processo para o qual os técnicos, muitas vezes, não se sentem preparados.

Essa também é a conclusão de Silva, Santos \& Souza (2012), que, discutindo a atuação dos ACS com saúde mental na ESF, destacam que o convívio próximo com a comunidade, ao mesmo tempo que permite uma "compreensão ampliada do contexto de vida dos usuários", gera sofrimento, pela "impotência experimentada em muitas situações e identificação com os problemas da comunidade" (p. 154).

\section{Acompanhar e prestar socorro em situações de risco}

Em continuidade ao diálogo anterior, Ana relata a experiência que ela e Marta tiveram com o acompanhamento de uma paciente que precisava de medicação assistida e que não dispunha de ajuda da família. Conta que um dia precisaram socorrer a paciente que estava sendo ameaçada pelo irmão, também doente mental, em um momento de crise. 
Ana:Agentejá até correu risco também com esse tipo de problema. Esquizofrênico, né, Joana?... A Marta levava remédio pra ela todo dia, porque ela morava num cômodo, no fundo, e a família inteira saía pra trabalhar, a irmã dava remédio pra ela só que ela jogava fora. Aí ela foi surtando, ficando mal, acho que no último estágio de loucura... Aí precisou fazer um acompanhamento. Aí eu e a Marta ia lá na casa dela todo dia, misturava o remédio ou no leite, ou na água né Marta?... e ficava olhando ela tomar. Levava pão, café, pra ela poder tomar essa medicação. Aí, um dia, chegamos na casa dela pra fazer isso e o irmão dela, também esquizofrênico, estava surtado, tava lá com ela, com uma barra de ferro dizendo que ia matar ela e quebrando a casa inteira. Aí a gente não sabia se chamava a polícia ou se entrava pra salvar ela...

Marta:Aí a gente entrou pra salvar ela...

Ana: Aí nós entramos lá correndo, pegamos ela, e saímos pra fora, chamamos a polícia e ele lá quebrando tudo, querendo bater em todo mundo...

Marta:Destruiu tudo a casinha dela... Mas a gente conseguiu uma grande coisa lá... Porque hoje a família dá remédio, leva ela na Saúde Mental... Antes não levava... Mas você vê, os pacientes têm uma confiança muito grande. (p. 9, L. 11-36)

Apesar de sustentar um discurso individualista da doença mental, que reduz a pessoa à condição de doente ("esquizofrênico," "ela foi surtando," "no último estágio da loucura") e que parece, nesse momento da interação grupal, servir ao propósito de construir a ação em saúde mental como um fardo difícil de carregar, a fala dos profissionais também sugere a existência de possíveis recursos para o trabalho em Saúde Mental. Inicialmente, relatam com detalhes uma postura de atenção e acompanhamento do paciente com transtorno mental, auxiliando no uso adequado da medicação e funcionando como rede social de apoio (Pinheiro, 2012). Em seguida, relatam uma intervenção em uma situação de crise, na qual, ainda que correndo riscos, protegem a paciente da crise agressiva de seu irmão. Identificam, nesse caso, que conseguiram uma mudança importante nos modos de posicionamento dessa família, que hoje se mostra mais envolvida e pode desenvolver o cuidado antes desenvolvido por elas. Embora tenham corrido risco, acreditam que esse tipo de atitude auxiliou na construção da confiança dos pacientes com a equipe de saúde.

\section{Construção de vínculos de confiança e respeito}

Na sequência, Vanessa valoriza o tempo de formação dessa equipe como um recurso para a construção do vínculo com as famílias e com a comunidade. Discutem, assim, que a experiência adquirida pela equipe permite a identificação do adoecimento e o reconhecimento da mudança no comportamento dessas pessoas. 
Joana: Então eu acredito que o papel do PSF é muito importante nessas áreas porque, eles pedem, nós estamos lá, parece o salva-vidas deles... Então a gente vai, corre, ajuda.

Vanessa: Já faz 8 anos que a equipe foi formada, que tá com a mesma equipe. A gente conhece eles, e sabe, assim, quando a gente vai visitar, pela história, a gente até comenta... A gente passa pra Joana, fala que acha que a pessoa tá entrando em depressão. Quem dá o diagnostico é o doutor, mas a gente acaba tendo essa visão, pela experiência, é onde a gente encaminha, marca uma consulta com o doutor. Porque a gente já vai percebendo que a pessoa tá depressiva. Tem uma, na minha área mesmo, que tá com problema de saúde, teve câncer na mama, e eu já to percebendo que pode ser essa história... Fez a reconstrução da mama, não deu certo e a autoestima dela tá lá embaixo, a gente tem percebido conversando que ela tá entrando em depressão mesmo, então já precisa de ajuda.(p. 10,L.4-27)

Como descrito por Joana e Vanessa, a proximidade com as pessoas permite que acompanhem as dificuldades (físicas e emocionais) que vivenciam de perto, funcionando como salva-vidas em muitas situações. Nesse exemplo, é clara a tentativa de atuação em uma perspectiva integral de saúde (Ayres, 2004; Cecilio, 2001; Pinheiro \& Mattos, 2006). Reconhecer as necessidades emocionais em tempo é significado como um recurso para evitar "um problema mais sério", o que só é possível porque conhecem bem as pessoas de quem cuidam e conquistaram seu reconhecimento.

Por outro lado: a não valorização dos recursos da equipe para o cuidado em Saúde Mental

Quando a pesquisadora perguntou para esses profissionais de saúde o que sentem ao lidar com esses pacientes, desconsideraram os recursos mencionados e posicionaram a equipe como frustrada e paralisada diante das demandas em Saúde Mental.

Pesquisadora: E quais são os sentimentos que surgem quando vocês atendem, lidam com uma pessoa com um problema de saúde mental?

Lia: Na verdade eu acho assim, quando você consegue fazer alguma coisa você sente um alívio que você conseguiu fazer alguma coisa, conseguiu resolver, mas quando você não consegue nada fica a frustração...

Tatiana: Não tem o que fazer...

Lia: É que assim, você não tem o que fazer e você fica assim... frustrada né... 
Vanessa: Sabe que tem que ajudar mas...

Lia: Não tem como...

Tatiana: Porque eles procuram muito a gente, principalmente porque a gente dá atenção, a gente escuta né e eles acham que a gente vai poder ajudar, resolver tudoe a gente não tem estrutura, não tem como resolver è̀s vezes passa pra gente mesmo o problema. (pp. 10-11)

Assim, a despeito de todos os recursos que a equipe demonstrou ter para o manejo das demandas em saúde mental, parece predominar o "discurso do déficit" (Gergen, 1997), o sentimento de frustração pelo que não pôde ser feito, pela falta de estrutura, pela aparente impossibilidade de uma ação resolutiva. Assim, embora valorizada pela comunidade, a equipe entende que tem poucos recursos para ajudar no cuidado em Saúde Mental, desqualificando a atenção e a escuta como parte importante e fundamental desse cuidado. Esse aspecto foi também observado por Pinheiro (2012) em pesquisa sobre o trabalho desenvolvido por agentes comunitários de saúde (ACS) na ESF.Em sua análise, o autor identificou um movimento bastante paradoxal nas práticas discursivas destes trabalhadores: embora valorizassem a construção de relações próximas e afetivas com a comunidade, centradas na escuta e no diálogo, frequentemente desvalorizavam sua atuação, descrevendo as mesmas como pouco efetivas e resolutivas.

Discutindo as possibilidades de articulação entre saúde mental e AB, Vecchia e Martins (2009b) focalizam a questão da desinstitucionalização dos cuidados nesse campo e destacam alguns componentes que podem auxiliar nessa articulação, tais como a melhoria do processo de comunicação entre profissionais, a necessidade de descentralização de ações, o questionamento acerca dos riscos de psiquiatrização do cuidado em saúde mental, a necessidade de superação de concepções culpabilizantes do grupo familiar e, por fim, a necessidade de investimento na capacitação dos profissionais da $A B$, com foco em uma visão ampliada de cuidado.

Em relação a esse último aspecto, nossa análise sugere que alguns recursos técnicos e relacionais que atravessam a construção do cuidado ao portador de doença mental na $\mathrm{AB}$ - como qualidade do vínculo, capacidade de escuta, diálogo - são subvalorizados. Há uma expectativa de resolutividade pouco condizente com a gravidade dos casos atendidos e uma aparente hierarquização das ações terapêuticas, que tende a privilegiar as ações de cunho medicamentoso em detrimento às tecnologias leves de cuidado (Merhy \& Franco, 2003), como acolhimento, construção de diálogo e vínculo. Estas ações, por sua vez, estão pautadas em uma concepção ampliada de cuidado, que articula seus aspectos técnicos a 
seus aspectos humanos, investindo a experiência do portador de uma doença mental de significado e valor (Ayres, 2004).

\section{Considerações finais}

Este estudo favorece a reflexão sobre aspectos importantes do cuidado em saúde mental na $A B$, sobretudo no que tange ao preparo e à capacitação das equipes de Saúde da Família para o trabalho nesse campo.

Em consonância com o que aponta Scóz e Fenili (2003) acerca da necessidade emergente da inserção da saúde mental na ESF pelo fato do aumento dos transtornos psíquicos leves, os profissionais entrevistados em nossa pesquisa trouxeram inúmeras situações em que se veem desafiados a atuarem nesse campo. No entanto, relataram sua participação também em situações de crise aguda, que exigem da equipe recursos teóricos e técnicos que sentem não possuir para o cuidado a esses pacientes.

Porém nossa análise apontou que, apesar das dificuldades certamente vividas por esses profissionais no desenvolvimento das ações de cuidado em saúde mental, e que evidenciam a necessidade de receberem apoio matricial, a conversa desenvolvida nos grupos também propiciou a emergência de muitos sentidos que indicam recursos para atuação nesse campo.

Como descrito em nossa análise, os profissionais entrevistados realizam desde o acompanhamento de pacientes em situação de crise a serviços especializados, assumindo uma postura de envolvimento e disponibilidade. Essa postura parece fortemente ancorada na concepção de "saúde como direito", levando também a outros serviços a cobrança de uma relação de maior compromisso com os usuários do sistema. Também reconhecem, muito claramente, a importância de se considerar os determinantes sociais da saúde, aproximando a noção de necessidades de saúde ao campo da saúde mental. Eles também valorizam o desenvolvimento de ações de prevenção e a necessidade de construção de relações de parceria com serviços especializados. Essa postura parece dar visibilidade para a importância de ações intersetoriais e interdisciplinares no cuidado em saúde/saúde mental, favorecendo o diálogo entre os diferentes níveis de atenção. Além disso, essa postura permite promover uma prática corresponsável também entre os serviços no acompanhamento longitudinal dos usuários no sistema de saúde. Ademais, há entre os profissionais entrevistados o investimento na construção de espaços de escuta e diálogo, sustentando uma postura condizente com a proposta de acolhimento e humanização (Brasil, 2006). Por fim, esses profissionais se empenham em construir vínculos de confiança e respeito como recursos para o cuidado 
em saúde mental, envolvendo desde o monitoramento dos pacientes em situações como a de uso contínuo de medicação psiquiátrica, até a mediação de relações familiares e construção de autonomia.

Embora tão diversos, necessários e fundamentais, esses recursos não foram reconhecidos por esses mesmos profissionais, que reforçaram o sentimento de fracasso, impotência e incapacidade para o cuidado em saúde mental.

Tal como analisam alguns pesquisadores, a ênfase no "discurso do déficit" (Gergen, 1997) traz consequências importantes para o modo como as pessoas entendem e vivenciam seu trabalho cotidiano, reforçando sentimentos de impotência, incompetência e fracasso, desfavoráveis a processos de transformação. Com base nessa compreensão, esses autores propuseram uma prática de trabalho com indivíduos, grupos e organizações denominada de Investigação Apreciativa (Cooperrider \& Whitney, 1998; Hammond, 1998), que busca auxiliar as pessoas no reconhecimento e nomeação de suas qualidades e histórias de sucesso e superação, buscando transformá-las em recursos para transformar realidades vividas como difíceis, desafiadoras e problemáticas.

Nosso estudo dá visibilidade para a importância de se construir espaços de diálogo nas equipes de trabalho, voltados à produção conjunta de conhecimento acerca do trabalho em saúde e, especialmente, de saúde mental. Contudo, valorizamos a importância de, nesses espaços, se privilegiar a dimensão processual da construção do conhecimento, assumindo posturas reflexivas e dialógicas, voltadas à revisão dos significados reificados, construídos pela equipe em relação a alguns temas e que impedem a transição para novos modos de compreensão de suas possibilidades de atuação em saúde (Guanaes \& Mattos, 2011). Para ilustrar com exemplos de nossa própria pesquisa, vários significados, se problematizados, poderiam ser analisados quanto às suas implicações para a construção de práticas sociais e, assim, possivelmente transformados - por exemplo, o uso repetitivo da expressão "pacientes surtados","esquizofrênico","no último estágio da loucura"; de que a ajuda social aos pacientes foi feita por "caridade, e não por obrigação"; a de que a unidade trabalha "apenas com prevenção" e"fiscalização", entre tantos outros.

Com base em nossa pesquisa, entendemos que pode ser especialmente útil as contribuições da Investigação Apreciativa (Cooperrider \& Whitney, 1998; Hammond, 1998) na coordenação desse trabalho com grupos nessa lógica, adotando uma escuta sensível aos recursos já possuídos pela equipe, em detrimento do reforço de suas deficiências e faIhas. Trata-se de uma mudança significativa no modo de se compreender os processos de capacitação profissional, tradicionalmente idealizados como modo de se desvendar as falhas no processo de trabalho e corrigi-las. Ao contrário, entendemos que ajudar a equipe no reconhecimento e nomeação desses recursos, possibilita a criação de novos vocabulários 
para compreenderem os desafios de seu cotidiano, criando condições para que os profissionais de saúde se apropriem de recursos e habilidades até então não reconhecidos como tal. É importante ressaltar que, em uma perspectiva construcionista, recursos não se referem a habilidades cognitivas ou possessões individuais. Ao contrário, têm a ver com "narrativas" de possibilidades. Entendemos que à medida que esses trabaIhadores ampliam suas narrativas sobre recursos, podem também ajudar os pacientes a ampliarem as suas próprias narrativas, construindo novos modos de relacionamento com os problemas em seu cotidiano.

Acreditamos que, assim como as equipes de saúde participantes de nossa pesquisa, muitas outras dispõem de recursos técnicos e relacionais - advindos de estudo, de prática e da própria experiência de vida - para o cuidado em saúde mental. No entanto, a falta de espaços de reflexão onde a equipe possa ser efetivamente cuidada em suas necessidades impede o reconhecimento desses recursos e a diminuição do sofrimento psíquico que os próprios profissionais de saúde enfrentam em suas tentativas de cuidar do outro. Concluímos que o investimento na criação de espaços grupais dialógicos onde as equipes de saúde da família possam reconhecer seus recursos e ampliar seu entendimento de cuidado pode contribuir para melhorar o atendimento em Saúde Mental na Atenção Básica.

\title{
Mental health care in the Family Health Strategy: Unrecognized resources
}

\begin{abstract}
Family Health Strategy (FHS) is one of the foundations of Primary Health Care. FHS offers a decentralized assistance in its referred territories, and attends different types of demands, including issues of mental health. This research aimed to make meanings with FHS professionals about their resources for mental health care. Thus, groups of discussion were conducted with these professionals in a town located in the state of São Paulo. Qualitative procedures of thematic analysis were conducted with the material, based on social constructionist contributions. This analysis highlights important technical and relational resources of the team regarding their practices with mental health, even though these resources were apparently little legitimized in their daily work. The need to create contexts for reflection among healthcare professionals where they can make new meanings about their actions is discussed. This may contribute to enhance the quality of mental health assistance in Primary Health Care.
\end{abstract}

Keywords: Primary health care. Family health strategy. Mental health. Social constructionism. 


\section{Soins de santé mentale dans la Stratégie pour la santé de la famille: les ressources non reconnues}

Résumé: L'un des piliers de la politique des Soins de santé primaires, la Stratégie pour la santé de la famille, effectue l'assistance décentralisée en répondant à des demandes diverses, la santé mentale y comprise. Cette recherche a visé à produire des sens avec les professionnels de la Santé de la famille concernant leurs ressources pour les soins de santé mentale. Pour le faire, des groupes de discussions ont été créés dans une ville de l'État de São Paulo. L'analyse de la matière a été réalisée par des méthodes qualitatives d'analyse thématique et basée sur les contributions du mouvement constructionniste social. Cette analyse a permis de mettre en évidence les importantes ressources techniques et relationnelles de l'équipe pour les soins de santé mentale, qui semblaient alors peu légitimées dans leur vie quotidienne. Nous avons discuté de la nécessité de créer des espaces de réflexion où les travailleurs de la santé puissent recadrer leurs actions, ce qui pourrait contribuer à améliorer les soins de santé mentale dans les Soins de santé primaires.

Mots-clés: Soins de santé primaires. Stratégie pour la santé de la famille. Santé mentale. Constructionnisme social.

\section{Atención a la salud mental en la Estrategia Salud de la Familia: los recursos no reconocidos}

Resumen: Uno de los pilares de la política de Atención Primaria, la estrategia Salud de la Familia realiza asistencia descentralizada en los territorios adscritos, atendiendo diferentes demandas, incluyendo la salud mental. Esa investigación tuve como objetivo producir sentidos con profesionales de la Salud de la Familia sobre sus recursos para el cuidado en salud mental. Por lo tanto, fueron realizados grupos de discusión con profesionales de la Salud de la Familia de un municipio del interior del Estado de Sao Paulo. El análisis ha permitido dar visibilidad a importantes recursos técnicos y relacionales del equipe para el cuidado en salud mental, pero que parecían poco legitimadas en su cotidiano. Discutimos la necesidad de creación de espacios de reflexión donde los trabajadores de salud puedan re significar sus atenciones, lo que puede contribuir para la calificación del cuidado en salud mental en la Atención Primaria.

Palabras-clave: Atención Primaria a la Salud. Estrategia Salud de la Familia. Salud Mental. Construccionismo Social.

Palabras clave: Atención primaria de salud. Estrategia de Salud Familiar. Salud mental. Construccionismo social. 


\section{Referências}

Amarante, A. L., Lepre, A. S., Gomes, J. L. D, Pereia, A. V., \& Dutra, V. F. D. (2011). As estratégias dos enfermeiros para o cuidado em saúde mental no programa saúde da família. Texto e Contexto-Enfermagem, 20(1), 85-93.

Ayres, J. R. C. M. (2004). O cuidado, os modos de ser (do) humano e as práticas de saúde. Saúde e Sociedade, 13(3), 16-29.

Brasil. Coordenação de Saúde Mental e Coordenação de Gestão da Atenção Básica. (2003). Saúde Mental e Atenção Básica: o vínculo e o diálogo necessários. Recuperado de: http://www.portal.saude.gov.br/portal/arquivos/pdf/diretrizes. pdf

Brasil. Ministério da saúde. Secretaria de Atenção à Saúde. Coordenação Geral de Saúde Mental. (2005). Reforma Psiquiátrica e Política de Saúde Mental no Brasil. OPAS. Recuperado de: http://portal.saude.gov.br/portal/arquivos/pdf/ relatorio_15_anos_caracas.pdf

Brasil. Ministério da Saúde. Política Nacional de Humanização. (2006). Humaniza SUS: Documento Base. Brasília, DF: Autor.

Brasil. Ministério da Saúde. (2007). Clínica ampliada equipe de referência e projeto terapêutico singular (2a ed.). Brasília, DF: Autor.

Brasil. Ministério da Saúde. (2009). Diretrizes do NASF. Cadernos de atenção básica, (n. 27). Brasília, DF: Autor.

Buss, P. M., \& Pellegrini Filho, A. (2007). A saúde e seus determinantes sociais. Phisis: Revista de Saúde Coletiva, 17(1),77-93.

Campos, G. W. S., \& Domitti, A. C. (2007). Apoio matricial e equipe de referência: uma metodologia para a gestão do trabalho interdisciplinar em saúde. Cadernos de Saúde Pública, 23(2), 399-407.

Campos, R. T. O, \& Gama, C. (2010). Saúde mental na Atenção Básica. In G. W. S. Campos \& A. V. P. Guerreiro (Orgs.), Manual de práticas de atenção básica: saúde ampliada e compartilhada (pp.210-236). São Paulo, SP: Hucitec.

Cecílio, L. C. O. (2001). As necessidades de saúde como conceito estruturante na luta pela integralidade e equidade na atenção em saúde. In R. Pinheiro \& R. A. Mattos (Orgs.), Os sentidos da integralidade na atenção e no cuidado à saúde (pp. 113-126). Rio de Janeiro, RJ: UERJ. 
Cooperrider, D. L., \& Whitney, D. (1998). When stories have wings: How "relational responsibility" opens new options for action. In S. Mcnamee \& K. Gergen (Eds.), Relational responsibility (pp. 57-64). Thousand Oaks, CA: Sage.

Correia, V. R., Barros, S., \& Colvero, L. A. (2011). Saúde mental na atenção básica: prática da equipe de saúde da família. Revista da Escola de Enfermagem da USP, 45(6), 1501-1506.

Egry, E. Y. (2008). Apresentação. In E. Y. Egry (Org.), Necessidades em saúde na perspectiva da atenção básica: guia para pesquisadores (pp. 9-10). São Paulo, SP: Dedone.

Figueiredo, M. D., \& Campos, R. O. (2008). Saúde mental e atenção básica a saúde: o apoio matricial na construção de uma rede multicêntrica. Saúde em Debate, $32(78,79,80), 143-149$.

Gergen, K. J. (1997). Realities and relationships: Soundings in social construction. Cambridge: Harvard University Press.

Gonçalves, P. L. (2000). A unidade de referência e a equipe volante. In A. D. Jatene, A. Lancetti \& S. A. F. Mattos (Orgs.), Saúde loucura: saúde mental e saúde da família (pp. 109-106). São Paulo, SP: Hucitec.

Guanaes, C., \& Mattos, A. T. R. (2011). Contribuições do movimento construcionista social para o trabalho com famílias na Estratégia Saúde da Família. Saúde e Sociedade, 20(4), 967-979.

Hammond, S. A. (1998). The thin book of appreciative inquiry (2a ed.). Bend, OR: Thin Book.

Kind, L. (2004). Notas para o trabalho com a técnica de grupos focais. Psicologia em Revista, 10(15), 124-136.

Lancetti, A. (2000). Saúde mental nas entranhas da metrópole. In A. D. Jatene, A. Lancetti \& S. A. F. Mattos (Orgs.), Saúde loucura: saúde mental e saúde da família (pp. 11-52). São Paulo, SP: Hucitec.

Llanes, G. D. (2005). Los grupos focales. Su utilidad para el médico de família. Revista Cubana de Medicina General Integral, 21(3-4).

Marqui, A. B. T., Jahn, A. C., Resta, D., G., Colomé, I., C., S., Rosa, N., \& Zanon, T. (2010). Caracterização das equipes da saúde da família e de seu processo de trabalho. Revista da Escola de Enfermagem da USP, 44(4), 951-961. 
McNamee, S., \& Hosking, D. M. (2012). Research and social change: A relational constructionist approach. New York: Routledge.

Merhy, E. E., \& Franco, T. B. (2003). Por uma composição técnica do trabalho centrada nas tecnologias leves e no campo relacional. Saúde em Debate, 27(65), 376-373.

Mielke, F. B., \& Olchowsky, A. (2010). Saúde mental na estratégia saúde da família: a avaliação de apoio matricial. Revista Brasileira de Enfermagem, 63(6), 900-907.

Mielke, F. B., \& Olchowsky, A. (2011). Ações de saúde mental na estratégia saúde da família e as tecnologias em saúde. Escola Anna Nery, 15(4), 762-768.

Oliveira, A. G. B., Ataide, I. F. C., \& Silva, M. A. (2004). A invisibilidade dos problemas de saúde mental na atenção primária: o trabalho da enfermeira construindo caminhos junto às equipes de saúde da família. Texto e Contexto- Enfermagem, 13(4), 618-624.

Pereira, W. A. B. (2000). Um psiquiatra, um projeto, uma comunidade. In A. D. Jatene, A. Lancetti \& S. A. F. Mattos (Orgs.), Saúde loucura: saúde mental e saúde da família (pp. 95-102). São Paulo, SP: Hucitec.

Pinheiro, R. L. (2012). A prática do agente comunitário de saúde com redes sociais na Estratégia Saúde da Família (Dissertação de Mestrado). Programa de PósGraduação em Psicologia, Faculdade de Filosofia, Ciências e Letras de Ribeirão Preto, Universidade de São Paulo, Ribeirão Preto.

Pinheiro, R., \& Mattos, R. A. (2006). Os sentidos da integralidade na atenção e no cuidado à saúde. Rio de Janeiro, RJ: ABRASCO.

Rabelo, I. V. M., \& Tavares, R. C. (2008). Homens-carrapatos e suas mulheres: relato de experiência em saúde mental na estratégia saúde da família. Saúde em Debate, $32(78 / 80), 133-142$.

Ribeiro, L. M., Medeiros, S. M., Albuquerque, J. S., \& Fernandes, S. M. B. A. (2010). Saúde mental e enfermagem na estratégia saúde da família: como estão atuando os enfermeiros? Revista da Escola de Enfermagem da USP, 44(2), 376-382.

Rosa, W. A. G., \& Labate, R. C. (2003). A contribuição da saúde mental para o desenvolvimento do PSF. Revista Brasileira de Enfermagem, 56(3), 230-235.

Scóz, T. M. X., \& Fenili, R. M. (2003). Como desenvolver projetos de atenção à saúde mental no programa de saúde da família. Revista Eletrônica de Enfermagem, 5(2), 71-77. 
Silva, C. B., Santos, J. E., \& Souza, R. C. (2012). Estratégia de apoio em saúde mental aos agentes comunitários de saúde de Salvador-BA. Saúde e Sociedade, 21(1), 153-160.

Shotter, J. (2005). Conversational realities revisited: Life, language, body and world. Chagrin Falls: The Taos Institute.

Souza, R. C. (2004). Produção de sentidos por profissionais de saúde da família acerca do doente mental e dos cuidados a ele dirigidos (Tese de Doutorado). Programa de Pós-Graduação em Enfermagem, Escola de Enfermagem de Ribeirão Preto, Universidade de São Paulo, Ribeirão Preto.

Souza, J., \& Luis, M. A. V. (2012). Demandas de saúde mental: percepção de enfermeiros de equipes de saúde da família. Acta Paulista de Enfermagem, 25(6), 852-858.

Spink, M. J. P., \& Menegon, V. (1999). A pesquisa como prática discursiva: superando os horrores metodológicos. In M. J. P. Spink (Org.), Práticas discursivas e produção de sentidos no cotidiano: aproximações teóricas e metodológicas (pp. 63-92). São Paulo, SP: Cortez.

Vecchia, M. D., \& Martins, S. T. F. (2009a). Concepções dos cuidados em saúde mental por uma equipe de saúde da família, em perspectiva histórico-cultural. Ciência e Saúde Coletiva, 14(1), 183-193.

Vecchia, M. D., \&Martins, S.T.F. (2009b). Desinstitucionalização dos cuidados a pessoas com transtornos mentais na atenção básica: aportes para a implementação de ações. Interface, 13(28), 151-164.

Recebido: 07/02/13

Aceito: 18/09/2013 